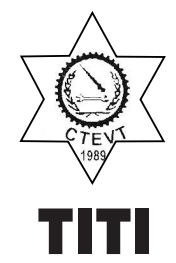

Editorial

ISSN: 2392-4578(Online)

\title{
Continuing the Journey of Education, Training and Research
}

\author{
Amit Koirala and Ekaraj Adhikari \\ Training Institute for Technical Instruction \\ Sanothimi, Bhaktapur, Nepal \\ Email for correspondence: editorial@titi.org.np
}

We are very happy to come up with the new issue of Journal of Training and Development (Issue 1, Volume 1) which has been published solely for the promotion of scholarship and research on training and development. We started our journey in 2009. We are now resuming this work of applied academic research and publication. We have significant lessons learnt from the past. At this point in time, we commit that we keep on publishing the journal regularly building on the commendable work carried out by our predecessors.

All the articles in this volume have been edited by a team of editors with ebullient spirit. Although there were tough challenges in editing articles, we dealt with them successfully in a team. We all concentrated on making this journal a forum for enhancing scholarly practices in the field of education, training and research especially in the field of Technical and Vocational Education and Training (TVET). We believe that the lessons learnt this time help to make better foundation of journal publication.

This issue consists of twelve articles on different aspects of training and development. The first article by Mr. Chet Nath Kandel explores issues associated with the intention of introducing TVET, its demand and supply side debates and opportunities and challenges of introducing TVET in the secondary schools of Nepal. This paper is based on literature review, interviews with some experts, and reflection of the author's own personal experiences. It concludes that TVET in school education system should continue as there is a high demand of TVET graduates in the job market.

Dr. Bhawani Shankar Subedi, in the second article, presents empirical assessment of effectiveness of teacher training programs to improve the quality of school education in Nepal. This article is executive summary of a comprehensive study conducted in 2009/2010 and concluded in March 2010. This study was based on mixed-methods approach- quantitative as well as qualitative approach. It concludes that the training of teachers has contributed and can positively influence quality of education if stakeholders are also actively involved in the education process and subsequent outcomes.

The issues of sustainable development are discussed in the third and the fourth articles of this journal. Ms. Shiba Bagale first talks about this in the context of technical and vocational education and training. Her paper is based on secondary sources of data. It has made an attempt to promote TVET from the perspectives of sustainable development highlighting on aspects of education and the barriers behind it. Likewise, Ms. Pramila Bakhati associates the issue of sustainable development with teacher education. She discusses the roles of teacher in promoting sustainable development through education. She argues that if knowledge is not transferred into behaviors or practice, that knowledge will be of little or no use.

The fifth article by Mr. Shree Prasad Devkota explores the necessity of TVET to empour conflict victims. 
It is a review paper solely based on secondary sources of data. The paper concludes that people oriented TEVT system should be tailored to their needs and circumstances.

Technical instructors' motivational practices are discussed by Mr. Amit Koirala and Ms. Gita Dhungana in the subsequent paper. They have presented the understanding of the key factors that enhance or hinder the instructors' motivation to teach in vocational training center. Case study research design was applied by the researchers. The paper concludes that fincial considerations and lack of academic soundness in school management committee were the major hindering factors for instructors' motivation. On the contrary, students' learning, achievement, performance were the major enhancing motivational factors.

The seventh article by Dr. Phanindra Kumar Chaudhary and Rajan Binayak Pasa appraises the possible importance of accessible agriculture education program in agriculture and rural development sector. Their article is based on library research. Their paper emphasizes that only formulating agriculture and rural development policies may not be enough to solve the existing socio-economic problems; it is necessary to diffuse agricultural education program in rural areas for producing skilled and knowledgeable workforce.

Mr. Anoj Bhattarai reflects on his schooling from engineering to training in the eighth article of this journal. He reflects highlighting the importance of setting goals for desired achievement in life. In addition, his paper scrutinizes the role of patronage of parents, societal influence and cultural capital to set the degree of success of a person.

Short term vocational skill test in Nepalese context is discussed by Mr. Rajan Binayak Pasa. His article assesses the possible contribution of short term vocational skill tested graduates and labor migration in foreign employment and contribution of remittance to Nepalese economy. The paper has made an attempt to assess the role of effective skill testing system that can be provided even at local levels for equal accessibility to all skilled workforce throughout the country.

The tenth article by Mr. Noor Jung Shah talks about the situation of children affected by AIDS as challenged learners in Nepal. This article is based on field experiences of the author. It also draws information from other secondary sources. The paper ends with the note that stigma and discrimination is the main cause for school dropout among children affected by AIDS and there are no specific strategies to intervene to make them continue education of such children.

The second last article of this journal discusses the subtle differences as well as common contents of job descriptions. Mr. Eka Raj Adhikari presents the process of developing job description in today's organizations. This review paper emphasizes the point that a job description can be used for multiple purposes. It has also opened interesting avenues for other researchers to explore further issues.

The last article by Mr. Anup Bhurtel is on the role of technical and vocational education and training in workforce development. The paper is based on library research. It has highlighted the contributions of TVET on employment in the labor market and uplifting of self-employment through the development of relevant skills.

Finally, we would like to express our thousands gratitude to the authors and the reviewers for their constant support in publishing the journal. We are also grateful to the entire TITI management team for their encouragement and support. It has become an open access journal through Nepal Journal Online. Readers from any part of the world can now access this journal. We are very grateful to Sioux Cumming for providing professional support to publish the journal online. Last but not least, we are very thankful to the publisher for the publication of the print version of this journal. 